\title{
Bromamine T, a stable active bromine compound, prevents the LPS-induced inflammatory response
}

\author{
STELLA BALIOU $^{1}$, MICHAEL SOFOPOULOS ${ }^{2}$, MARIA GOULIELMAKI ${ }^{1}$, DEMETRIOS A. SPANDIDOS ${ }^{3}$, \\ PETROS IOANNOU $^{4}$, ANTHONY M. KYRIAKOPOULOS ${ }^{5}$ and VASSILIOS ZOUMPOURLIS ${ }^{1}$ \\ ${ }^{1}$ National Hellenic Research Foundation, 11635 Athens; ${ }^{2}$ Department of Surgical Pathology, \\ Saint Savvas Anticancer Hospital of Athens, 11522 Athens; ${ }^{3}$ Laboratory of Clinical Virology, Medical School, \\ University of Crete, 71003 Heraklion; ${ }^{4}$ Department of Internal Medicine and Infectious Diseases, \\ University Hospital of Heraklion, 71110 Heraklion; ${ }^{5}$ Nasco AD Biotechnology Laboratory, 18536 Pireus, Greece
}

Received October 6, 2020; Accepted January 26, 2021

DOI: $10.3892 / \mathrm{ijmm} .2021 .4870$

\begin{abstract}
Inflammation is the most common cause of most acute and chronic debilitating diseases. Towards unveiling novel therapeutic options for patients with such complications, N-bromotaurine (TauNHBr) has emerged as a potential anti-inflammatory agent; however, its therapeutic efficacy is hindered due to its relatively poor stability. To address this challenge, the present study focused on examining the effects of a stable active bromine compound, named bromamine $\mathrm{T}$ (BAT). The present study examined the protective properties of BAT against lipopolysaccharide (LPS)-mediated inflammation in vitro, by using LPS-stimulated murine J774.A1 macrophages ( $\mathrm{M} \varphi \mathrm{s})$, as well as in vivo, by using a murine LPS-mediated air-pouch model. Additionally, its efficacy was compared with that of taurine, a known potent anti-inflammatory molecule. In LPS-stimulated J774A.1 M $\varphi$ s, BAT and taurine were very effective in reducing the secretion of pro-inflammatory mediators. The in vitro experiments indicated that LPS-mediated inflammation was attenuated due to the protective properties of BAT and of taurine, probably through the inhibition of phosphorylated p65 NF- $\kappa \mathrm{B}$ subunit (Ser 536) nuclear translocation. The in vivo experiments also revealed that BAT and taurine inhibited LPS-mediated inflammation by reducing total cell/polymorphonuclear cell (PMN) infiltration in the air-pouch and by decreasing pouch wall thickness. The analysis of exudates obtained from pouches highlighted that the inhibitory effects of BAT and taurine on the secretion of pro-inflammatory cytokines were similar to those observed in vitro. Notably, the effect of BAT at the highest concentration tested was superior to that of taurine
\end{abstract}

Correspondence to: Dr Vassilios Zoumpourlis, National Hellenic Research Foundation, 48 Vas. Konstantinou Avenue, 11635 Athens, Greece

E-mail: vzub@eie.gr

Key words: bromamine T, taurine, pro-inflammatory cytokines, air-pouch model of inflammation at the highest concentration. Taken together, the findings of the present study indicate that BAT prevents the LPS-induced inflammatory response both in vitro and in vivo.

\section{Introduction}

The innate immune response is primarily elicited to protect cells from infection or tissue injury, within minutes to hours. However, when the onset of inflammation continues for longer periods of time, chronic inflammation occurs and this contributes to the pathogenesis of diseases such as arthritis, cancer, cardiovascular and neurodegenerative diseases (1). The management of inflammatory diseases is often combatted with the use of non-steroidal anti-inflammatory drugs (NSAIDs), acting through the inhibition of cyclo-oxygenase 2 (COX-2) (2,3), corticosteroids (4), or immunomodulatory drugs (5). The therapeutic benefits of NSAIDs are counteracted by multiple side-effects that arise following chronic use or high doses. The chronic use of NSAIDs is related to cardiovascular and gastrointestinal toxicities (6), while high doses of these factors may cause renal dysfunction (7). On the other hand, prolonged corticosteroid use has several side-effects, such as metabolic dysregulation, osteoporosis, glaucoma etc. (8), while immunomodulatory drugs cause immunosuppression, that is often associated with infections (9).

Taurine is a non-essential amino acid that is abundant in all mammalian tissues $(10,11)$ and plays a significant role in homeostasis, since it is involved in the regulation of numerous vital cellular processes (osmoregulation, protein phosphorylation, membrane stability, bile acid conjugation, neuromodulation, maintenance of calcium concentration and the detoxification of xenobiotics) (12), thus ensuring the proper function of various organs. Furthermore, it has been demonstrated that taurine is effective against multiple types of inflammatory injury (13), including spinal cord injury (14), hepatic ischemia-reperfusion (15), lung injury $(16,17)$, ischemic stroke (18), lipopolysaccharide (LPS)-induced acute lung injury (16), 2,4,6-trinitrobenzene sulfonic acid (TNBS)-induced colitis (19) and dextran sodium sulfate (DSS)-induced colitis $(20,21)$. The anti-inflammatory effects of taurine are usually attributed to its antioxidant effects (13), 
which are evidenced by the inhibition of lipid peroxidation (22) and by its membrane-stabilizing capacity (23).

During inflammation, taurine can be conjugated with hypobromous acid $(\mathrm{HOBr})$, generating $N$-bromotaurine (TauNHBr) from either activated neutrophils or eosinophils $(24,25)$. TauNHBr has been proven to attenuate inflammatory conditions in a more efficient manner than that elicited by taurine (26). The anti-inflammatory capacity of TauNHBr is highly associated with i) its capacity to hinder phagocyte function and to impair the respiratory burst (26); ii) the reduction of various pro-inflammatory mediators [tumor necrosis factor- $\alpha$ (TNF- $\alpha$ ), interleukin (IL)-6, IL-1 $\beta$, IL-8 and IL-12], nitric oxide $(\mathrm{NO})$, prostaglandin $\mathrm{E}_{2}\left(\mathrm{PGE}_{2}\right)$ and chemokines in both rodent and human leukocytes (27-31); iii) the inhibition of nuclear factor $\kappa \mathrm{B}(\mathrm{NF}-\kappa \mathrm{B})$ activity (27); and iv) the induction of heme-oxygenase-1 (HO-1) expression in various cell types (3), including J774A.1 macrophages (M $\varphi s$ ) (32) or rheumatoid arthritis fibroblast-like synovial cells (33). From a clinical perspective, TauNHBr has been proven to be beneficial in the treatment of acne vulgaris (34), herpes zoster (35), in the local treatment of periodontal diseases, and in the elimination of oral biofilm pathogens (36).

However, TauNHBr exhibits weak therapeutic effectiveness in vivo due to its poor stability and its rapid degradation in the blood (37). To overcome this issue, bromamine T (BAT; chemical structure, $\left[\mathrm{CH}_{3}-\mathrm{C}_{6} \mathrm{H}_{4}-\mathrm{SO}_{2}-\mathrm{N}-\mathrm{Br}\right]^{-} \mathrm{Na}^{+} \times 2 \mathrm{H}_{2} \mathrm{O}$ ), which is a stable active bromine compound (38), was synthesized (39). BAT, the sodium salt of $N$-bromo-4-toluenesulfonamide, was the result of the reaction of chloramine $\mathrm{T}$ with elemental bromine at the Institute of Hygiene and Medical Microbiology of the Medical University of Innsbruck by Professor Dr Waldemar Gottardi according to the method of Nair et al (39). BAT has been illustrated to exert anti-inflammatory and anti-microbial effects to a similar extent as those of TauNHBr (38). In particular, BAT retains potent anti-microbial, anti-inflammatory and anti-cancer potential in vitro $(38,40)$. The anti-inflammatory effect of BAT is mediated by reducing the protein expression levels of TNF- $\alpha$, IL- 6 and IL-12p40, with its most prominent effect emerging in the inhibition of IL-12p40 protein expression, as confirmed by enzyme-linked immunosorbent assay (ELISA) experiments (38).

BAT has been successfully used in a case of multi-bacterial scalp infection (41). Furthermore, BAT has also been used in patients with acne vulgaris, exerting comparable effects to those of clindamycin, a commonly used anti-microbial (34).

The aim of the present study was to examine the protective properties of BAT against LPS-mediated inflammation in vitro, by using murine J774.A1 M 95 , and in vivo, by using a murine LPS-mediated air-pouch model. Herein, the putative effects of BAT were compared with those of taurine.

\section{Materials and methods}

Agents. Taurine (chemical structure, $\mathrm{C}_{2} \mathrm{H}_{7} \mathrm{NO}_{3} \mathrm{~S}$ or $\mathrm{NH}_{2} \mathrm{CH}_{2} \mathrm{CH}_{2} \mathrm{SO}_{3} \mathrm{H}$ ) was purchased from AppliChem ITW Companies (Taurine BioChemica, A1140,1000, Lot $3 \mathrm{M} 004589)$. The purity was $>99 \%$ and the molecular weight was $125.15 \mathrm{~g} / \mathrm{mol}$. BAT (chemical structure, $\mathrm{C}_{7} \mathrm{H}_{7} \mathrm{BrNNaO}_{2} \mathrm{~S}$ x $2 \mathrm{H}_{2} \mathrm{O}$ or $\left[\mathrm{CH}_{3}-\mathrm{C}_{6} \mathrm{H}_{4}-\mathrm{SO}_{2}-\mathrm{N}-\mathrm{Br}\right]^{-} \mathrm{Na}^{+}$x $\left.2 \mathrm{H}_{2} \mathrm{O}\right)$ was kindly provided by the laboratories of Professor Dr Waldemar
Gottardi and Professor Dr Markus Nagl at the Institute of Hygiene and Medical Microbiology of the Medical University of Innsbruck (Bromamine T, Lot no 29/06/2016). BAT ( $N$-bromo-4-toluenesulfonamide sodium salt, BAT x $2 \mathrm{H}_{2} \mathrm{O}$ ) was prepared by the reaction of chloramine $\mathrm{T}$ with elemental bromine according to the method of Nair et al (39). The specifications were a potency of $95.8 \%$, a bromine content of $24.83 \%$ and an effective molecular weight of $322.02 \mathrm{~g} / \mathrm{mol}$. As a result, Nair et al (39) demonstrated the synthesis of BAT and Walczewska et al (38) demonstrated that BAT was a stable active bromine compound.

Cells and cell culture. The J774.A1 murine M $\varphi$ s were obtained from the laboratories of Professor Dr Waldemar Gottardi and Professor Dr Markus Nagl at the Institute of Hygiene and Medical Microbiology of the Medical University of Innsbruck. All the cells were cultured in Dulbecco's modified Eagle's medium (DMEM, 41966-029; Gibco; Thermo Fisher Scientific, Inc.). All culture media were supplemented with 10\% fetal bovine serum (FBS, 16000-044; Gibco; Thermo Fisher Scientific, Inc.) and antibiotics (100 IU/ml penicillin and $100 \mu \mathrm{g} / \mathrm{ml}$ streptomycin) (full DMEM). The cells were grown in a humidified incubator with $5 \% \mathrm{CO}_{2}$ at $37^{\circ} \mathrm{C}$. The J774.A1 M $\varphi$ s were pre-incubated with various concentrations of the tested agents (BAT or taurine), diluted in pure DMEM without FBS for $1.5 \mathrm{~h}$ at $37^{\circ} \mathrm{C}$. Subsequently, $100 \mathrm{ng} / \mathrm{ml}$ of LPS were diluted in full DMEM and were administered to the M $\varphi s$ for an additional $24 \mathrm{~h}$ at $37^{\circ} \mathrm{C}$, as previously described (38). Data are presented as the means \pm SEM of 3 independent experiments.

RNA extraction and reverse transcription-quantitative polymerase chain reaction ( $R T-q P C R)$. Total RNA isolation from the cultured $\mathrm{M} \varphi \mathrm{s}$, as well as exudates derived from the pouches of LPS-exposed mice (model described below), was carried out using TRIzol reagent (Invitrogen; Thermo Fisher Scientific, Inc.). The RNA quality was confirmed, through the presence of 28s, 18s and 5s RNA ribosomal subunits in agarose gel electrophoresis and taking into consideration the ratio of OD260/280 to be approximately 2 as well as the ratio of OD260/230 to be approximately 2.2 in all samples.

Reverse transcription was performed from $1.0 \mu \mathrm{g}$ of purified RNA using the SuperScript Reverse Transcriptase II (Invitrogen; Thermo Fisher Scientific, Inc.) following the manufacturer's instructions. Quantification at the mRNA level was conducted in 96-well polymerase chain reaction (PCR) plates using a Bio-Rad iCycler and the iQ5 Multicolor Real-Time polymerase chain reaction (RT-PCR) detection system (Bio-Rad Laboratories, Inc.). Each reaction contained 1X IQ SYBR-Green Supermix (Bio-Rad Laboratories, Inc.) and $150 \mathrm{nmol} / \mathrm{l}$ of each primer. All genes were tested in triplicate. The results were analyzed on the iCycler software. Values were normalized against $\beta$-actin. The relative quantification of complementary DNA (cDNA) was performed according to the $\Delta \Delta \mathrm{Cq}$ method (42). Selected primers are presented in Table SI.

Immunofluorescence. To detect the putative suppressive effect of BAT or taurine on the nuclear translocation of phosphorylated NF- $\mathrm{B}$ p 65 protein (Ser 536), immunofluorescence experiments were performed. In detail, 24-well plates were 
seeded overnight with $4.5 \times 10^{4}$ cells/well. The cells were pre-treated with $0.1-0.5 \mathrm{mM}$ BAT or $100 \mathrm{mM}$ taurine diluted in pure DMEM without FBS for $1.5 \mathrm{~h}$ at $37^{\circ} \mathrm{C}$. Subsequently, LPS (100 ng/ml) diluted in full DMEM was added to each well, and the cells were incubated for $24 \mathrm{~h}$ at $37^{\circ} \mathrm{C}$, as previously described (38). The M $\varphi$ s were washed with $1 \mathrm{X}$ phosphate-buffered saline (PBS) for 5 min and fixed with $4 \%$ paraformaldehyde (PFA) at room temperature for $10 \mathrm{~min}$. The fixed cells were permeabilized with $1 \times \mathrm{PBS} / 0.5 \%$ Triton $\mathrm{X}-100$ for $5 \mathrm{~min}$ at $4{ }^{\circ} \mathrm{C}$ and blocked with $1 \% \mathrm{BSA} / 1 \mathrm{X}$ PBS, diluted in $1 \mathrm{X} \mathrm{PBS}$ at room temperature. The $\mathrm{M} \varphi s$ were then incubated with the primary anti-phospho-NF-кB-p65 monoclonal antibody (mAb; \#3033; Cell Signaling Technology, Inc.) diluted in 1\% BSA/1X PBS at $4^{\circ} \mathrm{C}$ overnight. The following day, the cells were incubated with $(4 \mu \mathrm{g} / \mathrm{ml})$ Alexa Fluor 488-labeled secondary antibody (A11008; Thermo Fisher Scientific, Inc.) diluted in 1\% BSA/1X PBS for $1 \mathrm{~h}$ at room temperature, after washing with 1X PBS. Hoechst dye No. 33342 (B2261; Sigma-Aldrich Merck KGaA; $0.5 \mu \mathrm{g} / \mathrm{ml}$ ) was used for cellular chromatin staining. Finally, the coverslips were mounted in Prolong Gold antifade media (Molecular Probes, Inc.) and the cells were observed under a confocal microscope (Leica Microsystems $\mathrm{GmbH}$ ) with an excitation wavelength of $355 \mathrm{~nm}$ for Hoechst and with an excitation wavelength of $488 \mathrm{~nm}$ for phosphorylated NF- $\kappa \mathrm{B}$ (Ser 536). The LAS AF program was used to acquire the images. Experiments were repeated independently 3 times and representative images are presented.

Mice. Male black C57BL/6 mice (20 g in weight, 6 weeks of age) were obtained from the National Hellenic Research Foundation and housed under controlled temperature $\left(22 \pm 2^{\circ} \mathrm{C}\right)$ and photoperiod (12 h light; $12 \mathrm{~h}$ dark) with free access to water and food. All experiments with mice were performed in the authorized animal house of the National Hellenic Research Foundation (License no. EL 25 BIObr 031 as a breeding facility; License no. EL 25 BIOsup 032 as a supply facility; and License no. for EL 25 BIOexp 033 as a research installation). The experiments complied with the Protocol on the Protection and Welfare of Animals, as obliged by the rules of the National Hellenic Research Foundation the regulations of the National Bioethics Committee and article 3 of the presidential decree 160/1991 (in line with 86/609/EEC directive) regarding the protection of experimental animals. A total of 3 mice/group were used. The minimum number of animals was achieved according to the 3Rs (replacement, reduction and refinement), to ensure scientific and statistical validity. The health and behaviour of the animals were monitored daily. The mice were gradually euthanized, using carbon dioxide $\left(\mathrm{CO}_{2}\right)$. The gradual flow rate of $\mathrm{CO}_{2}$ was as per the guidelines. The death of the animals was confirmed through the verification of cardiac and respiratory arrest.

Ethics approval. The present study was conducted according to the guidelines of the Declaration of Helsinki and was approved by the Bioethics Committee of the National Hellenic Research Foundation (date of approval: 29/3/2020). The ethic code is PN 2-3/29-3-2020.

LPS-induced air pouch murine model of inflammation. Air-pouches were created according to a modified method described in the study by Sedgwick et al (43). An area of dorsal skin $\left(4 \mathrm{~cm}^{2}\right)$ was shaved, and $3 \mathrm{ml}$ of sterile air were subcutaneously injected to establish a single air-pouch in 6-week-old black (C57BL/6) mice. The mice were anaesthetized by an intraperitoneal (i.p) injection of ketamine at $100 \mathrm{mg} / \mathrm{kg}$ together with xylazine at $10 \mathrm{mg} / \mathrm{kg}$, prior to the subcutaneous injections during the LPS-induced air-pouch model of inflammation. The mice weighed approximately $20 \mathrm{~g}$ and were housed in filtered-air laminar-flow cabinets at a controlled temperature $\left(22 \pm 2^{\circ} \mathrm{C}\right)$ with a 12 -h light/dark cycle. A total of $3 \mathrm{ml}$ of sterile air were administered on alternate days to maintain the pouch. At 10 days after air-pouch formation, the pouches were injected with a single dose of $1 \mathrm{ml}(1 \mu \mathrm{g} / \mathrm{ml})$ LPS alone (positive control) or a single dose of $1 \mathrm{ml}(1 \mu \mathrm{g} / \mathrm{ml})$ LPS plus a single dose of ( 3 or 6 or $9 \mathrm{mg} /$ mouse) BAT concurrently or a single dose of $1 \mathrm{ml}(1 \mu \mathrm{g} / \mathrm{ml})$ LPS plus a single dose of ( $9 \mathrm{mg} / \mathrm{mouse}$ ) taurine concurrently, inside the air pouches of the mice for $8 \mathrm{~h}$, as previously described (44). Each group was composed of 3 mice. This air pouch model of inflammation has been similarly used in a wide range of studies (44-48). Inflammatory exudates were then harvested by collecting the lavage fluids after washing the air-pouch cavities with $2 \mathrm{ml}$ PBS (1X, pH 7.4) followed by RNA extraction. The pouch membranes were fixed in $10 \%(\mathrm{v} / \mathrm{v})$ buffered formalin for histological analysis.

Histological analysis. Ten days after air-pouch formation, substances were administered and after $8 \mathrm{~h}$, mice were euthanized and their pouches were dissected, sampled and processed for paraffin embedding. The protocol for paraffin embedding was as follows (total $16 \mathrm{~h}): 70 \%$ ethanol $(2 \mathrm{~h})$, $80 \%$ ethanol $(1 \mathrm{~h}), 95 \%$ ethanol $(1 \mathrm{~h}), 100 \%$ ethanol $(4.5 \mathrm{~h})$, xylene $(4.5 \mathrm{~h})$, paraffin $\left(58-60^{\circ} \mathrm{C}\right)(4 \mathrm{~h})$, embedding tissues into paraffin blocks and trimming into the suitable $6 \mu \mathrm{m}$. Sections were then stained with hematoxylin $(8 \mathrm{~min})$ and eosin (1 min) (H\&E) at $30^{\circ} \mathrm{C}$, using the following protocol: The sections were deparaffinized, and treated with absolute alcohol (10 min), 95\% alcohol (2 min), 70\% alcohol (2 min) and stained with Harris hematoxylin solution (Thermo Fisher Scientific, Inc.) (8 min) and saturated lithium carbonate $(1 \mathrm{~min})$ at $30^{\circ} \mathrm{C}$. After rinsing, the sections were counterstained with eosin-phloxine solution (Thermo Fisher Scientific, Inc.) (1 min) and dehydrated using 95\% alcohol. Microphotographs were captured using a Nikon Eclipse 80i upright microscope with CFI60 lenses, using a Leica DFC 450 C digital camera. The magnification utilized for their capture was $\mathrm{x} 200$. In each section, pouch wall thickness was measured at 6 regions randomly at the upper, at the back and at the middle side of the pouch wall. The mean of six different regions in each section was determined. The thickness of the pouch and the area of the corresponding region were calculated using ImageJ software (v1.52a). The total cell number (based on nucleus count) was calculated as cells $/ \mathrm{mm}^{2}$, using the 'analyze particles' feature of Image J software, in LPS-exposed mice bearing air-pouch with or without treatment, manually. The number of PMNs was calculated per $\mathrm{mm}^{2}$, in LPS-exposed mice bearing air pouch with or without treatment, manually.

Statistical analysis. Data are presented as the means \pm SEM. One-way ANOVA, followed by Tukey's multiple 
comparison test was used to evaluate the significance of all experiments between the LPS group with the LPS/BAT and LPS/taurine-treated groups. Two-way ANOVA was used to evaluate the statistical significance of weights between the LPS group with the LPS/BAT group and LPS/taurine group. Statistics were calculated with GraphPad Prism 6.0 (GraphPad Software, Inc.).

\section{Results}

$B A T$ reduces the $m R N A$ expression levels of pro-inflammatory mediators in LPS-stimulated J774.A1 M $\varphi$ s at lower concentrations compared to taurine. To investigate the putative inhibitory effects of BAT and taurine on the LPS-induced inflammatory response in vitro, the mRNA expression levels of various pro-inflammatory cytokines secreted by J774.A1 $\mathrm{M} \varphi s$ were assessed following $1.5 \mathrm{~h}$ of incubation with either BAT or taurine alone, prior to their stimulation with LPS for $24 \mathrm{~h}$. In the present study, RT-qPCR was used to detect the mRNA expression levels of TNF- $\alpha$, IL-1 $\beta$, IL-18 and IL-23 following treatment of J774.A1 M $\varphi$ s with either $(0.1,0.3,0.5$, 1 and $1.75 \mathrm{mM}$ ) BAT or (100 and $200 \mathrm{mM})$ taurine prior to their stimulation with LPS for $24 \mathrm{~h}$. Of note, BAT and taurine exerted potent protective effects against inflammation, by reducing the mRNA expression levels of pro-inflammatory cytokines in the LPS-stimulated J774.A1 M $\varphi$ s (Fig. 1 and Table SII). In particular, the IL-1 $\beta$ mRNA levels were decreased by $(51,59$, $59,60,81,59$ and $71 \%$ ), the IL-23 mRNA levels by $(68,70,73$, $75,81,72$ and $77 \%)$, the IL-18 mRNA levels by $(15,25,50,57$, $81,15$ and $55 \%)$ and the TNF- $\alpha$ mRNA levels by $(56,79 \%, 83$, $89,96,88$ and $89 \%)$ in the $(0.1,0.3,0.5,1$ and $1.75 \mathrm{mM})$ BAT-, and in the (100 and $200 \mathrm{mM}$ ) taurine-treated LPS-stimulated J774.A1 M $\varphi s$ compared to the LPS-stimulated M $\varphi$ s. A dose-dependent transcriptional downregulation in the levels of pro-inflammatory cytokines was proved in the BAT-treated LPS-stimulated J774.A1 M $\varphi$ s, with the highest inhibitory effect observed at the concentration of 1.75 mM BAT. Notably, the highest suppression of IL-1 $\beta$, IL-23 and IL-18 mRNA expression (81\%) and the greatest inhibition of TNF- $\alpha(96 \%)$ were evidenced in the $1.75 \mathrm{mM}$ BAT-treated $\mathrm{M} \varphi s$ prior to the induction of LPS-mediated inflammation. In all cases, the 1.75 mM BAT-treated LPS-stimulated J774.A1 M $\varphi 5$ exhibited a greater transcriptional inhibition of all pro-inflammatory cytokines than those of the 100 and $200 \mathrm{mM}$ taurine-treated LPS-stimulated J774.A1 M $\varphi$ s. As a result, BAT potentially exerted a more significant protective action than taurine, by hindering the LPS inflammatory stimulus to activate cytokine secretion from macrophages. These data were consistent with the reduced protein expression levels of pro-inflammatory mediators (IL-6, IL12p40, TNF- $\alpha$ ), as previously indicated by ELISA experiments in LPS-stimulated J774.A1 M $\varphi s$ (38).

$B A T$ inhibits the nuclear translocation of the phosphorylated $N F-\kappa B$ p65 subunit in LPS-stimulated J774.A1 M $\varphi$ s. To elucidate the molecular mechanisms underlying the protective effects of BAT and taurine against LPS-mediated-inflammation, immunofluorescence experiments were employed to examine the exact localization of phosphorylated NF- $\mathrm{B}$ p 65 subunit (Ser536) in the J774A.1 M $\varphi s$. The dynamics (serine 536 phosphorylated p65 subunit of $\mathrm{NF}-\kappa \mathrm{B}$ ) were measured in BAT- or taurine-treated J774.A1 M $\varphi$ s, prior to their stimulation with LPS. Following treatment with BAT or taurine, the nuclear translocation of phospho-NF- $\kappa$ B p65 subunit (Ser 536) was hindered in a dose-dependent manner, since it was mainly found in the cell cytoplasm (Fig. 2). In particular, the inhibition of phospho-NF- $\kappa$ B p65 (Ser 536) nuclear translocation dynamics emerged in the $0.1 \mathrm{mM}$ BAT-treated J774.A1 M $\varphi$ s prior to their stimulation with LPS, while the most effective inhibition of NF- $\kappa$ B p65 phosphorylation (Ser 536) was observed in the $0.5 \mathrm{mM}$ BAT-treated J774.A1 M $\varphi$ s prior to their stimulation with LPS, as compared to the LPS-stimulated J774A.1 M $\varphi$ s. Of note, the levels of phosphorylated NF- $\kappa \mathrm{B}$ p 65 in the NC J774.A1 M $\varphi \varsigma$ were similar to those of LPS-stimulated J774A.1 M $\varphi s$ following BAT or taurine treatment. As a result, BAT and taurine restored not only the translocation, but also the levels of phosphorylated NF- $\kappa$ B p65 in the LPS-stimulated J774A.1 $\mathrm{M} \varphi s$, as observed in the NC M $\varphi$ s. It was hypothesized that the sequestration of $\mathrm{p}-\mathrm{NF}-\kappa \mathrm{B}$ p65 subunit (Ser 536) occurs in the cytoplasm of J774.A1 M $\varphi$ s following BAT or taurine treatment, prior to their stimulation with LPS, probably due to other post-translational modifications or other mechanisms

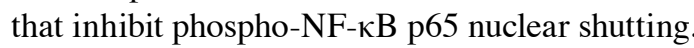

BAT attenuates the LPS inflammatory response to a greater extent than taurine. To confirm the protective effects of BAT and taurine against LPS-mediated inflammation in vivo, the LPS-induced air-pouch model of inflammation was used. This animal model has been widely used to evaluate acute inflammation due to its high sensitivity and cost-efficiency (41). In the present analysis, 4 groups of C57BL/6 mice were subjected to the following procedure: They were subjected to air-pouch formation subcutaneously; air injections were administered on specific days according to the timeline to maintain the air-pouch. At 10 days after air pouch formation, LPS inflammatory stimulus and optionally BAT or taurine were administered to the mice for $8 \mathrm{~h}$. To elucidate the potential protective effect of BAT against LPS-induced inflammation in vivo, we compared its impact with that of a known anti-inflammatory agent, namely taurine. The 4 groups of animals were composed as follows: Group 1, mice with an air-pouch and treated with saline; group 2, LPS-exposed mice with an air pouch; group 3, BAT-treated LPS-exposed mice with an air pouch; and group 4, taurine-treated LPS-exposed mice with an air pouch. To ensure that the presence of inflammation formed inside the air-pouch, the results derived from the normal saline-negative control (NC) and the LPS-treated group (LPS) were compared. Following the induction of inflammation, the functional significance of either BAT or taurine in orchestrating the distribution of inflammatory cell populations and in determining the mRNA expression levels of pro-inflammatory cytokines was elucidated.

Air-pouch tissues were stained with H\&E to evaluate the histological presence of various inflammatory cell populations. The injection of $(1 \mu \mathrm{g} / \mathrm{ml})$ LPS into the air-pouch on the backs of mice for $8 \mathrm{~h}$ resulted in increased inflammatory cell infiltration and elevated pouch wall thickness. All the examined parameters in the LPS group were significantly increased compared with those in the NC group (Fig. 3 and Table SIII). Representative images with histological changes in the pouch wall (synovial membrane and connective tissue) 
A

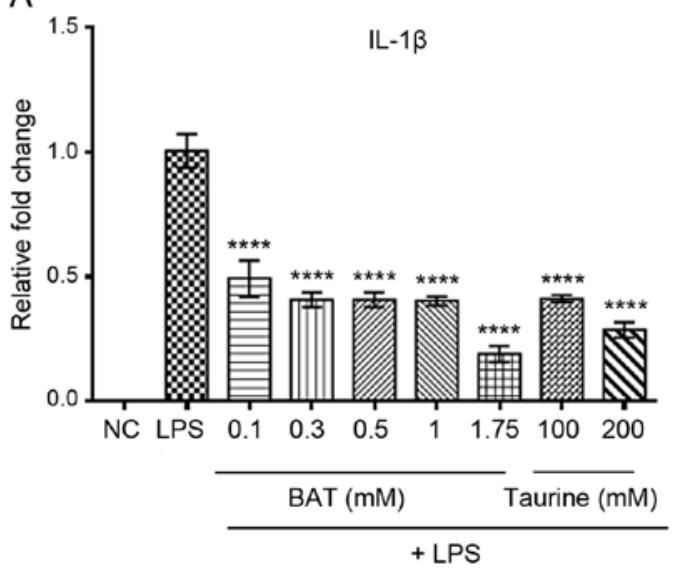

C

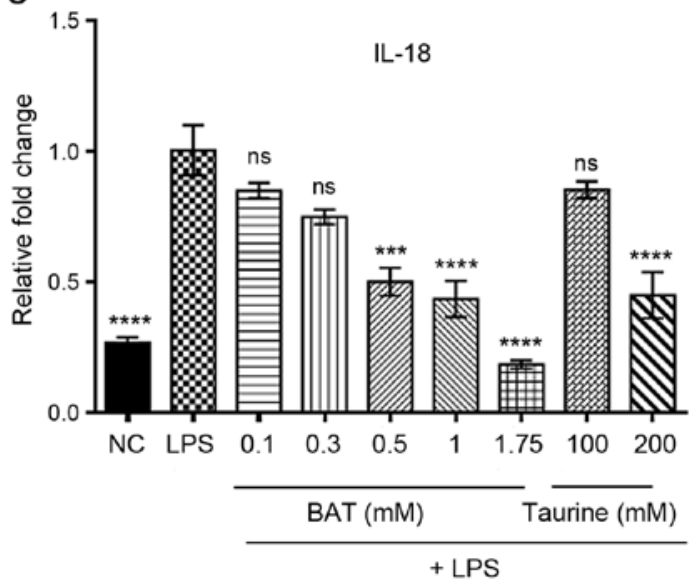

B

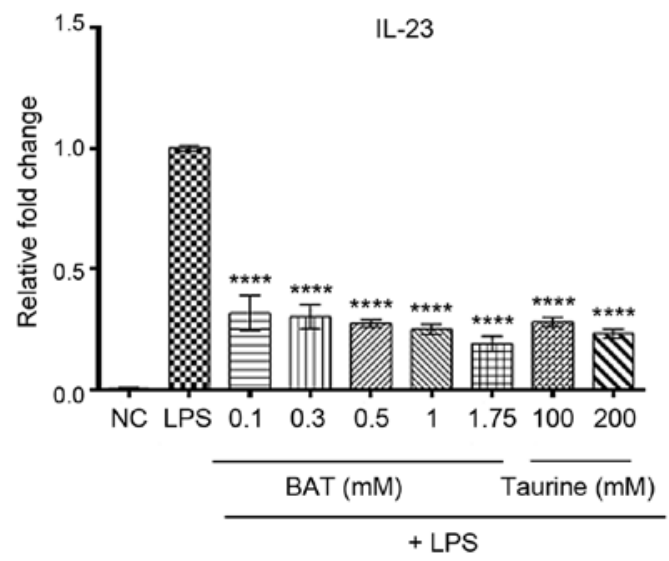

D

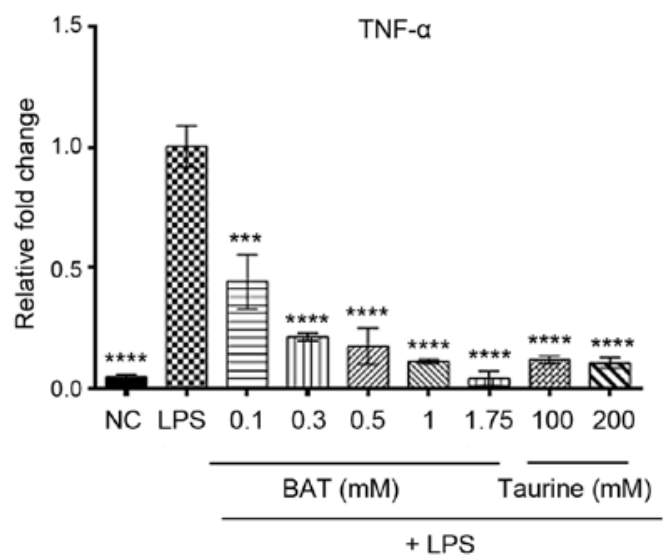

Figure 1. BAT exerts an anti-inflammatory effect in vitro, through the transcriptional downregulation of pro-inflammatory cytokines. RT-PCR analysis of interleukins (A) IL-1 $\beta$, (B) IL-23, (C) IL-18, (D) TNF- $\alpha$ mRNA levels in the LPS-stimulated J774.A1 M 9 following (0.1-1.75 mM) BAT or (100-200 mM) taurine treatment for $1.5 \mathrm{~h}$. In particular, the groups of J774.A1 M $\varphi$ s were the following: Negative control (NC), (100 ng/ml) LPS-stimulated J774.A1 M $\varphi s$ (LPS group), (100 ng/ml) LPS plus 0.1 mM BAT-treated J774.A1 M $\varphi s$ (LPS + $0.1 \mathrm{mM}$ BAT group), (100 ng/ml) LPS plus 0.3 mM BAT-treated J774.A1 M $\varphi s$ (LPS + 0.3 mM BAT group), (100 ng/ml) LPS plus $0.5 \mathrm{mM}$ BAT-treated J774.A1 M $\varphi$ (LPS + $0.5 \mathrm{mM}$ BAT group), (100 ng/ml) LPS plus $1 \mathrm{mM} \mathrm{BAT-treated}$ J774.A1 M $\varphi s$ (LPS + $1 \mathrm{mM}$ BAT group), (100 ng/ml) LPS plus $1.75 \mathrm{mM}$ BAT-treated J774.A1 M $\varphi s$ (LPS + $1 \mathrm{mM}$ BAT group), (100 ng/ml) LPS plus $100 \mathrm{mM}$ taurine-treated J774.A1 M $\varphi$ s (LPS + $100 \mathrm{mM}$ taurine group), (100 ng/ml) LPS plus $200 \mathrm{mM}$ taurine-treated J774.A1 M $\varphi s$ (LPS + $200 \mathrm{mM}$ taurine group). Data are presented as the means \pm SEM of 3 independent experiments. One-way ANOVA analysis followed by Tukey's multiple comparison test revealed the statistically significant differences between LPS alone-treated J774.A1 M $\varphi$ s with LPS/BAT-treated M $\varphi \varsigma$ and LPS/taurine-treated M $\varphi$. Statistical analysis revealed the comparison of BAT and taurine-treated M $\varphi$ s compared to LPS-treated M $\varphi \varsigma$; ns, not significant, ${ }^{* * *} \mathrm{P}<0.001,{ }^{* * * *} \mathrm{P}<0.0001$ vs. LPS-stimulated M $\varphi \varsigma$. M $\varphi$, macrophages; LPS, lipopolysaccharide; BAT, bromamine T.

in the differently treated groups compared to the LPS group are presented in Fig. 3B. In particular, the LPS-exposed mice bearing an air pouch treated with BAT or taurine had a fewer number of infiltrating cells, as well as polymorphonuclear cells (PMNs) in the pouch wall (synovial membrane and connective tissue) and thinner pouch wall formation than those injected with LPS alone (Fig. 3 and Table SIII). Notably, pouch wall thickness was similar between the LPS and $9 \mathrm{mg}$ BAT-treated mice bearing an air-pouch and the LPS and $9 \mathrm{mg}$ taurine-treated mice bearing an air-pouch (Fig. 3G). The analysis of the exudates obtained from the pouches also revealed that the inhibitory effects of BAT and taurine treatment on the secretion of pro-inflammatory cytokines (Fig. 4 and Table SIV) were similar to those observed in vitro (Fig. 1 and Table SI). In particular, the LPS-exposed mice bearing an air pouch and treated with 3 or 6 or $9 \mathrm{mg}$ of BAT or $9 \mathrm{mg}$ of taurine exhibited decreased IL-1 $\beta$ mRNA levels by 48,81 , 91 and $84 \%$, decreased IL-23 mRNA levels by 19,93, 94 and $39 \%$, and decreased IL-18 mRNA levels by $26,63,86$ and $87 \%$ respectively, as compared to the untreated LPS-exposed mice bearing an air pouch. The IL-17 mRNA levels were reduced by $34,51,78$ and $80 \%$ following treatment of the LPS-exposed mice bearing an air pouch with 3,6 and $9 \mathrm{mg}$ of BAT and $9 \mathrm{mg}$ of taurine, respectively, compared to those of untreated LPS-exposed mice bearing an air pouch. Similarly, the TNF- $\alpha$ mRNA levels were reduced by $19,53,86$ and $73 \%$ in the pouch exudates obtained from the LPS-exposed mice and treated with 3,6 and $9 \mathrm{mg}$ of BAT or $9 \mathrm{mg}$ of taurine, respectively, as compared to those of untreated LPS-exposed mice bearing an air pouch. Last but not least, the mRNA levels of thymic stromal lymphopoietin (TSLP) were suppressed by 17, 61, 85 and $87 \%$ in the LPS-exposed mice with the air pouch treated with 3,6 and $9 \mathrm{mg}$ of BAT or $9 \mathrm{mg}$ of taurine, respectively, as compared to those of untreated LPS-exposed mice bearing an air pouch. At the transcriptional level, IL-1 $\beta$, IL-23 and TNF- $\alpha$ were produced at lower levels in the LPS plus $9 \mathrm{mg}$ BAT-treated mice bearing an air pouch compared to those in the LPS plus $9 \mathrm{mg}$ taurine-treated mice bearing an air pouch (Fig. 4A, 


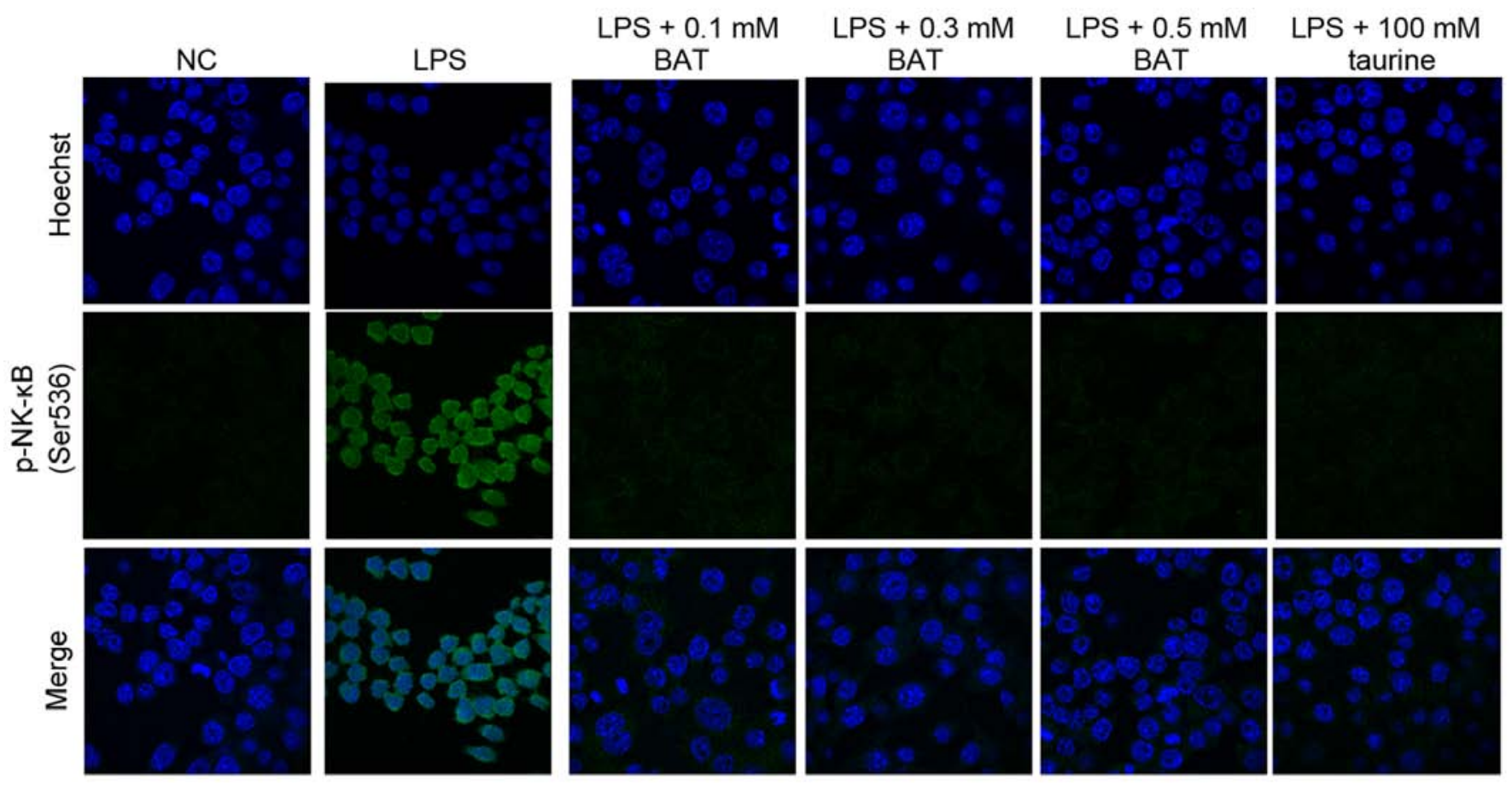

Figure 2. BAT inhibits nuclear the translocation of phosphorylated NF- $\mathrm{B}$ p65 subunit. Immunofluorescence of phosphorylated NF- $\mathrm{B}$ p65 subunit (Ser 536) in the LPS-stimulated J774.A1 M $\varphi s$ after (0.1-0.5 mM) BAT or $100 \mathrm{mM}$ taurine treatment for $1.5 \mathrm{~h}$. The phosphorylated NF- $\mathrm{B}$ p65 was detected by Alexa Fluor 488-labeled immunostaining (green); nuclei were stained with Hoechst (blue). Untreated cells were used as a negative control (NC), while cells treated only with LPS were used as a positive control for an inflammatory response (x630 magnification). In particular, the groups of J774.A1 M $\varphi \varsigma$ were the following: Negative control (NC), (100 ng/ml) LPS-treated J774.A1 M $\varphi s$ (LPS group), (100 ng/ml) LPS plus 0.1 mM BAT-treated J774.A1 M $\varphi s$ (LPS + 0.1 mM BAT group), (100 ng/ml) LPS plus 0.3 mM BAT-treated J774.A1 M $\varphi s$ (LPS + 0.3 mM BAT group), (100 ng/ml) LPS plus 0.5 mM BAT-treated J774.A1 M $\varphi s$ (LPS + $0.5 \mathrm{mM}$ BAT group), (100 ng/ml) LPS plus $100 \mathrm{mM}$ taurine-treated J774.A1 M $\varphi s$ (LPS + $100 \mathrm{mM}$ taurine group). M $\varphi 5$, macrophages; LPS, lipopolysaccharide; BAT, bromamine $\mathrm{T}$.

B and E). Notably, the LPS plus $6 \mathrm{mg}$ BAT-treated mice bearing an air pouch exhibited very low transcriptional levels of IL-23, as opposed to the LPS plus $9 \mathrm{mg}$ taurine-treated mice bearing an air pouch (Fig. 4B). As regards the transcriptional levels of IL-18, IL-17 and TSLP, the 2 groups of LPS plus $9 \mathrm{mg}$ of BAT and LPS plus $9 \mathrm{mg}$ of taurine-treated mice bearing an air pouch presented similar values (Fig. 4C and F). Of note, the inhibitory effect of $9 \mathrm{mg}$ BAT was the most effective on the IL-23 mRNA levels in the LPS-exposed mice bearing an air pouch (Fig. 4B). As a result, the LPS plus $9 \mathrm{mg}$ BAT-treated mice bearing an air pouch exhibited a superior effect on the majority of the pro-inflammatory cytokines tested and on cellular infiltration, compared to the aforementioned parameters of the LPS plus $9 \mathrm{mg}$ taurine-treated mice bearing an air pouch.

\section{Discussion}

It is well established that taurine exerts a potent anti-inflammatory effect (26); however, its use in clinical practice is limited. This evidence has prompted researchers to evaluate the anti-inflammatory effect of taurine derivatives, such as TauNHBr, which comprises the reaction product of taurine with $\mathrm{HOBr}$ at the inflammatory site (26). It has been reported that TauNHBr is employed in the treatment of inflammatory and infectious diseases, but its clinical efficacy is obstructed by high rates of degradation (26). For this reason, BAT was designed as the stable active bromine compound (38) and its molecular mechanisms in inflammation are under investigation. In the previous study by Walczewska et al (38), the anti-inflammatory activity of BAT was examined, starting from a concentration of $0.1 \mathrm{mM}$. Based on those findings, the present study examined the protective properties of BAT against LPS-induced inflammation in a concentration range of 0.1-1.75 mM. Moreover, the biocompatibility index of BAT (namely the ratio of the minimal concentration exerting in vitro cytotoxicity in cell culture to the minimal one exerting in vitro killing activity against bacteria) ranges approximately between 1 and even 100 (38). On the other hand, in the study by Sartori et al (49), taurine did not exhibit any significant anti-inflammatory activity in macrophages that were pre-treated with up to $10 \mathrm{mM}$ of taurine; thus, in the present study, a higher dose was used to examine the potential protective activity of taurine against LPS-mediated inflammation, given that taurine is a non-essential amino-acid in the human setting (50).

The results of the present study indicated that the protective effect of BAT was superior to that of taurine in vitro using LPS-stimulated J774.A1 M $\varphi$ s through the attenuation of pro-inflammatory mediator mRNA expression. The current in vitro observations were in accordance with the results of in vivo experiments, as discussed below.

Initially, the results proved that BAT accounted for the reduction of pro-inflammatory cytokines (IL-1 $\beta$, IL-23, IL-18 and TNF- $\alpha$ ) at the transcriptional level, in LPS-stimulated J774. A1 M $\varphi s$ to a greater extent than taurine, through the inhibition of the translocation of phosphorylated NF- $\mathrm{KB}$ p65 subunit (Ser536) in the nuclei. Accordingly, the anti-inflammatory 
A

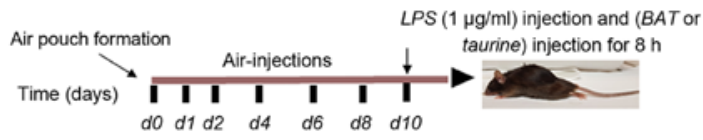

B

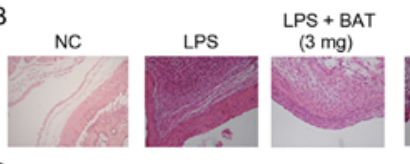

Cells of connective tissue
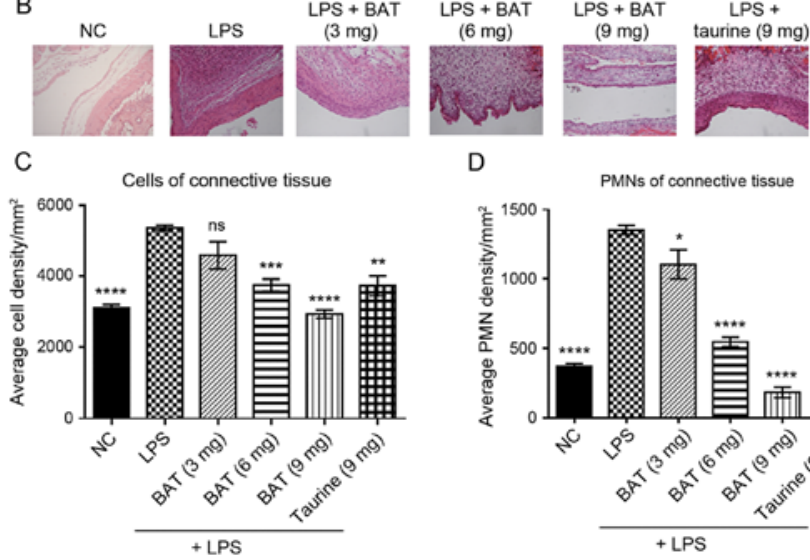

D

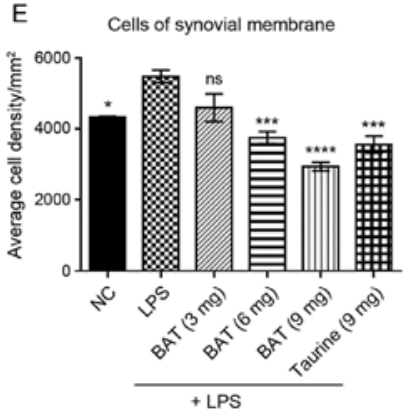

$\mathrm{F}$

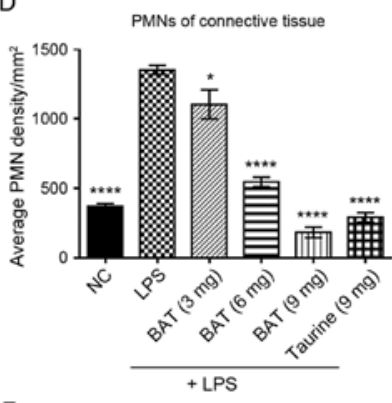

PMNs of synovial membrane
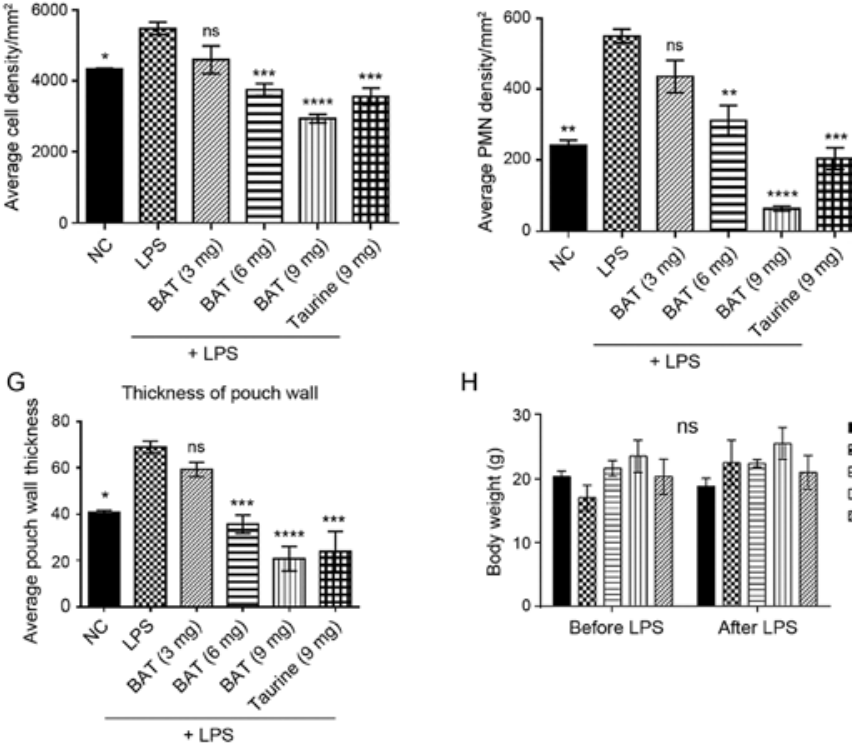

$\mathrm{H}$

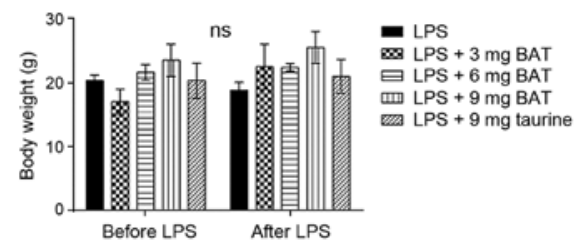

Figure 3. BAT acts as an anti-inflammatory agent in the LPS-induced air pouch model of inflammation in vivo, through the inhibition of total cellular infiltration and PMN recruitment. (A) Schematic experimental design. All the groups of mice were subjected to the following procedure: They were subjected to air pouch formation subcutaneously, air injections were administered on specific days according to the timeline to mice to maintain the air pouch, and (1 $\mu \mathrm{g} / \mathrm{ml})$ LPS inflammatory stimulus was administered to the mice at 10 days following air pouch formation. The LPS group was compared with (1 $\mu \mathrm{g} / \mathrm{ml}) \mathrm{LPS}$ and $(3$ or 6 or $9 \mathrm{mg}$ ) BAT-treated group and with $(1 \mu \mathrm{g} / \mathrm{ml})$ LPS and $(9 \mathrm{mg})$ taurine-treated group for $8 \mathrm{~h}$. Each group was composed of 3 mice. (B) Representative histological images of the pouch wall including synovial membrane and connective tissue in all groups of mice (x200 magnification), using H\&E staining. In particular, the groups of mice were as follows: Negative control (NC), $(1 \mu \mathrm{g} / \mathrm{ml})$ LPS-treated mice (LPS group), (1 $\mu \mathrm{g} / \mathrm{ml})$ LPS plus (3 mg) BAT-treated mice (LPS $+3 \mathrm{mg}$ BAT group), $(1 \mu \mathrm{g} / \mathrm{ml})$ LPS plus $(6 \mathrm{mg})$ BAT-treated mice (LPS $+6 \mathrm{mg}$ BAT group), $(1 \mu \mathrm{g} / \mathrm{ml})$ LPS plus $(9 \mathrm{mg})$ BAT-treated mice (LPS $+9 \mathrm{mg}$ BAT group), $(1 \mu \mathrm{g} / \mathrm{ml}$ ) LPS plus ( $9 \mathrm{mg}$ ) taurine-treated mice (LPS $+9 \mathrm{mg}$ taurine group). (C) Graphical representation of the semi-quantified total cell distribution derived from the connective tissue of experimental groups. One-way ANOVA followed by Tukey's multiple comparison test revealed the statistically significant differences between the LPS-treated group with LPS/BAT-treated group and LPS/taurine-treated group; ns, not significant, ${ }^{* *} \mathrm{P}<0.01,{ }^{* * *} \mathrm{P}<0.001$, ${ }_{* * * * *} \mathrm{P}<0.0001$ vs. the LPS-stimulated group. (D) Graphical representation of the semi-quantified polymorphonuclear cell (PMNs) distribution derived from the connective tissue of experimental groups. Each group was composed of 3 mice. One-way ANOVA followed by Tukey's multiple comparison test revealed the statistically significant differences between the LPS-stimulated group with LPS/BAT-treated group and LPS/taurine-treated group; ${ }^{*} \mathrm{P}<0.05,{ }^{* * * * *} \mathrm{P}<0.0001 \mathrm{vs}$. the LPS-stimulated group. (E) Graphical representation of the semi-quantified total cell distribution derived from the synovial membrane of experimental groups. Each group was composed of 3 mice. One-way ANOVA followed by Tukey's multiple comparison test revealed the statistically significant differences between the LPS-stimulated group with LPS/BAT-treated group and LPS/taurine-treated group; ns, not significant, ${ }^{*} \mathrm{P}<0.05,{ }^{* * * *} \mathrm{P}<0.001,{ }^{* * * * * *} \mathrm{P}<0.0001$ vs. the LPS-stimulated group. (F) Graphical representation of the semi-quantified PMN distribution derived from the synovial membrane of experimental groups Each group was composed of 3 mice. One-way ANOVA followed by Tukey's multiple comparison test revealed the statistically significant differences between the LPS-stimulated group with the LPS/BAT-treated group and LPS/taurine-treated group; ns, not significant, ${ }^{* * *} \mathrm{P}<0.01,{ }^{* * * *} \mathrm{P}<0.001,{ }^{* * * * *} \mathrm{P}<0.0001$ vs. the LPS-stimulated group. (G) Quantification of pouch wall thickness on each section in all experimental groups of mice. Random $100 \mu \mathrm{m}$ longitudinal pouch areas were selected to count total cells, and the mean of 6 different areas within each section was determined. LPS treatment was used as a positive control of inflammation. The results of untreated (NC) mice are also presented. Each group was composed of 3 mice. One-way ANOVA followed by Tukey's multiple comparison test revealed the statistically significant differences between the LPS-stimulated group with the LPS/BAT-treated group and LPS/taurine-treated group; ns, not significant, ${ }^{\mathrm{P}} \mathrm{P}<0.05,{ }^{* * * *} \mathrm{P}<0.001,{ }^{* * * *} \mathrm{P}<0.0001$ vs. the LPS-stimulated group. (H) Graphical representation of mouse body weights, following treatment with either BAT or taurine. BAT or taurine-treated mice did not present any difference in body weight. Each group was composed of 3 mice. Two-way ANOVA did not reveal any statistically significant differences between groups; ns, not significant. LPS, lipopolysaccharide; BAT, bromamine T; PMN, polymorphonuclear cell. 
A

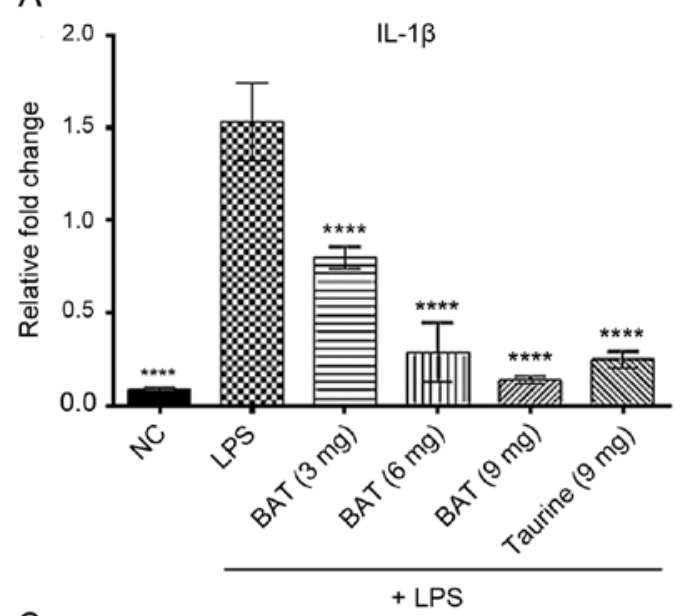

C

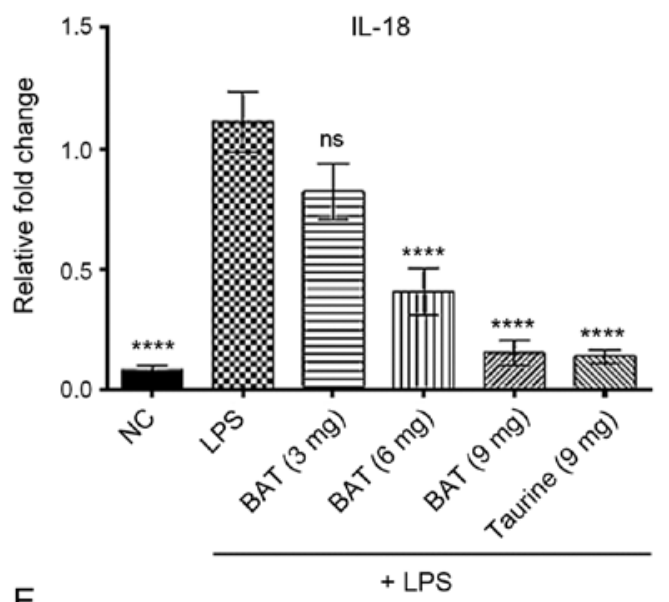

E

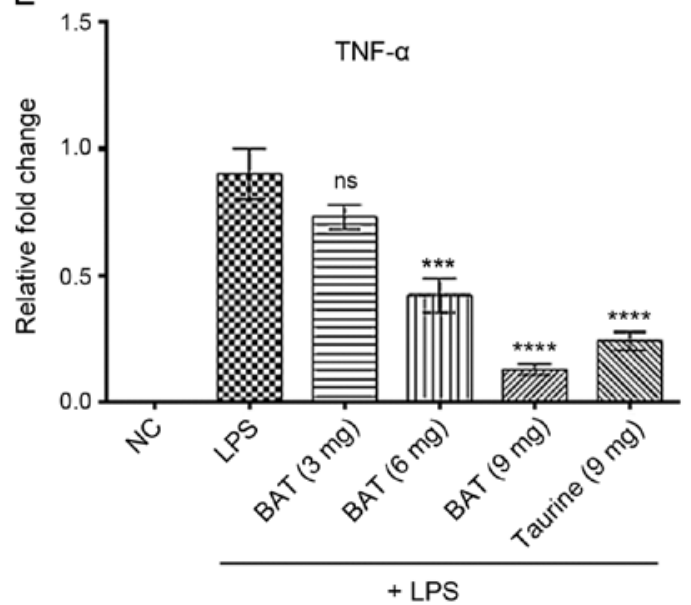

B
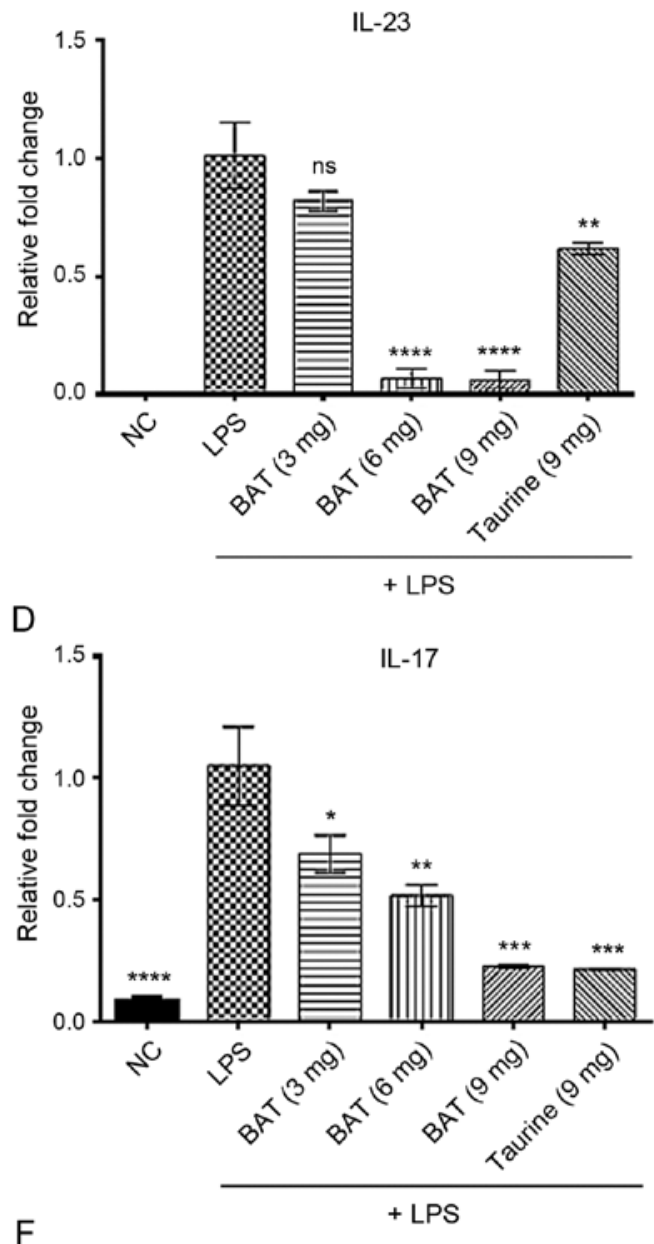

$\mathrm{F}$

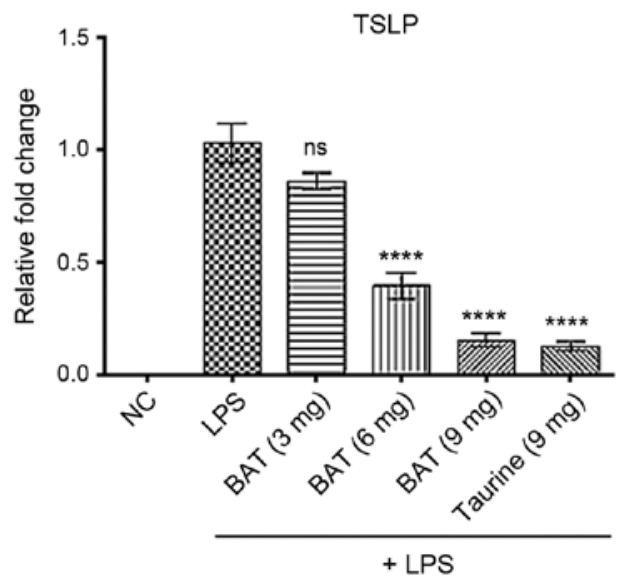

Figure 4. BAT exerts an inhibitory effect on the transcription of pro-inflammatory cytokines in the LPS-induced air-pouch model of inflammation in vivo. RT-PCR analysis of (A) IL-1 $\beta$, (B) IL-23, (C) IL-18, (D) IL-17, (E) TNF- $\alpha$, and (F) TSLP in (3 or 6 or 9 mg) BAT or (9 mg) taurine-treated LPS-exposed mice with air-pouch compared to LPS-exposed mice bearing air-pouch. In particular, the groups of mice were as follows: Negative control (NC), $(1 \mu \mathrm{g} / \mathrm{ml})$ LPS-treated mice (LPS group), $(1 \mu \mathrm{g} / \mathrm{ml})$ LPS plus ( $3 \mathrm{mg}$ ) BAT-treated mice (LPS $+3 \mathrm{mg}$ BAT group), $(1 \mu \mathrm{g} / \mathrm{ml})$ LPS plus (6 mg) BAT-treated mice (LPS + $6 \mathrm{mg}$ BAT group), $(1 \mu \mathrm{g} / \mathrm{ml})$ LPS plus $(9 \mathrm{mg})$ BAT-treated mice (LPS $+9 \mathrm{mg}$ BAT group), $(1 \mu \mathrm{g} / \mathrm{ml})$ LPS plus $(9 \mathrm{mg})$ taurine-treated mice (LPS $+9 \mathrm{mg}$ taurine group). Each group was composed of 3 mice. One-way ANOVA analysis followed by Tukey's multiple comparison test revealed the statistically significant differences between the LPS-treated group with the LPS/BAT-treated group and LPS/taurine-treated group; ns, not significant, ${ }^{*} \mathrm{P}<0.05,{ }^{* * *} \mathrm{P}<0.01,{ }^{* * * *} \mathrm{P}<0.001$, ${ }_{* * * * *}<0.0001$ vs. the LPS-stimulated group. LPS, lipopolysaccharide; BAT, bromamine T.

properties of BAT have been observed in J774.A1 M $\varphi$, through the suppression of the protein expression of TNF- $\alpha$, IL12p40 and $\mathrm{PGE}_{2}(33)$.

Secondly, a murine air-pouch model was used to evaluate the protective effects of BAT on LPS-induced inflammation, through relative qualitative and quantitative information about inflammatory cell infiltration. Multiple inflammatory stimuli have been used for the induction of inflammation, such as LPS, rHuPH20, HA, Hyal type I-S and IV-S, zymosan, carrageenan $(44,48,51,52)$. The model of LPS-induced acute 
inflammation differs from other established models, due to its greater reproducibility, the paucity of any visible side-effects and its dependence on the activity of TNF- $\alpha$, IL-1 $\beta$ and myeloperoxidase (MPO) (41). In the experiments presented herein, the potential protective action of agents was examined $8 \mathrm{~h}$ following the LPS administration, since a significant neutrophil accumulation was only observed $8 \mathrm{~h}$ after the LPS injection in mice bearing an air pouch (44). A similar pattern of LPS challenge was also used in another study (53). In the present study, pouches were injected with a single dose of $1 \mathrm{ml}(1 \mu \mathrm{g} / \mathrm{ml})$ LPS alone (positive control) or a single dose of $1 \mathrm{ml}(1 \mu \mathrm{g} / \mathrm{ml})$ LPS plus a single dose of ( 3 or 6 or $9 \mathrm{mg} / \mathrm{mouse}$ ) BAT concurrently or a single dose of $1 \mathrm{ml}(1 \mu \mathrm{g} / \mathrm{ml})$ LPS plus a single dose of ( $9 \mathrm{mg} / \mathrm{mouse}$ ) taurine concurrently, inside the air pouch of mice for $8 \mathrm{~h}, 10$ days after air pouch formation (44). Each group was composed of 3 mice. In the current experimental set-up, LPS-exposed mice bearing an air pouch exhibited an increase in the inflammatory cell infiltration and the pouch wall thickness compared to the NC mice bearing an air pouch. To validate the putative protective role of BAT against LPS-induced inflammation, its effects were compared with those of taurine. The results proved that cellular density of synovial membrane or connective tissue, pouch wall thickness and PMNs of synovial membrane or connective tissue in BAT- or taurine-treated groups, were significantly lower compared to the LPS group. The highest inhibitory effect on the pro-inflammatory parameters was observed with $9 \mathrm{mg}$ of BAT and was superior to that mediated by $9 \mathrm{mg}$ of taurine on LPS-exposed mice bearing an air pouch. Notably, these results proved the potent protective properties of BAT against LPS-mediated inflammation in vivo, given that M $\varphi s$ and fibroblasts are accumulated, promoting the formation of granulation tissue and subsequent collagen synthesis in the LPS-induced air pouch model of inflammation (54). In the in vivo experiments, higher concentrations of BAT were used relative to the in vitro experiments. The possible presence of compounds with amino groups (ammonium, amino acids, peptides and proteins), could allow the mixture of bromamine compounds to be formed by transfer of bromine, while in the presence of reducing substances ( $\mathrm{S}-\mathrm{H}$ compounds, thiosulfate), BAT could be transformed to toluenesulfonamide and, therefore, could be inactivated (personal communication with Professor Dr M. Nagl at the Institute of Hygiene and Medical Microbiology of the Medical University of Innsbruck).

BAT and taurine provided a protective environment, attenuating the possibility of inflammation caused by LPS, not only by reducing pouch wall thickness and total cellular infiltration, but also through the suppression of the mRNA expression of IL-1 $\beta$, IL-23, IL-18, IL-17, TNF- $\alpha$ and and TSLP (Fig. 4). However, the IL-6 mRNA expression levels were not measured in the in vitro and in vivo experiments in the present study, since protein expression levels of IL- 6 previously appeared to be reduced in the J774A.1 M $\varphi$ s following BAT treatment (38). To study the expression pattern of specific pro-inflammatory mediators according to the applied LPS stimulus, one of the most important pro-inflammatory mediators (TNF- $\alpha$ ), which is secreted from immune cells (such as M $\varphi s, \mathrm{~T}$, and B lymphocytes) in response to LPS was evaluated (55). The present study also examined the expression pattern of IL-1 $\beta$, which is secreted by either immune or stromal cells, constituting an important mediator of inflammation (56). It is well-established that the synergistic activation of TNF- $\alpha /$ IL-1 $\beta$ mediates acute inflammatory reactions, by inducing the expression of adhesion molecules, thus enriching the circulating leukocytes in the inflamed site (57). The inhibitory effect of either BAT or taurine on pro-inflammatory cytokines (TNF- $\alpha$ and IL-1 $\beta$ ) should be specially considered since TNF- $\alpha$ and IL- $1 \beta$ have shown to play an important role in the activation of endothelial cells by increasing the expression of adhesion molecules, including intercellular adhesion molecule 1 (ICAM-1) and vascular cell adhesion protein 1 (VCAM-1), which are crucial for leukocyte recruitment (58). The results of the present study were consistent with these data, indicating that taurine is capable of reducing the expression levels of ICAM-1 and VCAM-1 in endothelial cells induced by hypoxia through the p38 mitogen-activated protein kinase (MAPK) pathway (59). Similarly, hyperglycemia-mediated endothelial dysfunction is ameliorated by taurine, through interference with adhesion molecules (60). In the present study, the analysis of the specific cytokines was conducted only in LPS-induced air-pouch model since TSLP is secreted by either synovial fibroblasts (61) or bone marrow-derived dendritic cells (DCs) (52) and IL-17 is secreted by either $\mathrm{CD}^{+}{ }^{+} \mathrm{T}$ helper (Th) cells $(62)$ or neutrophils $(63,64)$ in response to LPS inflammatory stimulus. In all cases of pro-inflammatory mediators, the protective effect of BAT was proven against LPS-mediated inflammation. In some cases, the superiority of BAT over taurine could be associated with the fact that BAT is an inducer of the anti-inflammatory molecule hemo-oxygenase-1 (HO-1) (38). Furthermore, BAT reduces COX-2 levels, thus, reducing the production of inflammatory mediators (3).

In the previous study by Walczewska et al (38), ELISA experiments in LPS-stimulated J774.A1 M $\varphi$ s revealed reduced protein expression levels of pro-inflammatory mediators (IL-6, IL12p40 and TNF- $\alpha$ ) following pre-treatment with 0.1-0.3 mM BAT. In the present study, it was firstly demonstrated that BAT was more effective than taurine in preventing LPS-induced inflammation through a marked decline of mRNA expression levels of pro-inflammatory mediators in vitro. In LPS-stimulated J774.A1 M 9 s, the underlying molecular mechanism relies on the activation of the transcription factor $\mathrm{NF}-\kappa \mathrm{B}$, a master regulator of pro-inflammatory cytokine production. To the best of knowledge, this is the first study to demonstrate that BAT prevents the mRNA expression levels of pro-inflammatory cytokines in J774.A1 M $\varphi s$, via the inhibition of the translocation of the phosphorylated $\mathrm{NF}-\kappa \mathrm{B}$ p65 subunit (Ser536) in the nuclei and its subsequent cytoplasmic sequestration to similar extent as NC M $\varphi s$. In addition, the present study provides a comprehensive overview regarding the protective properties of BAT or taurine against LPS-mediated inflammation in vivo. In particular, the present study provides convincing evidence that BAT is superior to taurine in vivo, by repressing the transcription of the majority of pro-inflammatory cytokines to a greater extent, and by reducing the total cell/PMN infiltration in the air pouch of LPS-exposed mice to a greater extent. As a result, it is demonstrated that BAT, an active bromine compound, is able to inhibit LPS-mediated inflammation in vitro and in vivo. The in vitro findings raise the next reasonable challenge, whether primary macrophages derived from in vivo experiments on LPS-inflammation can get activated and comply with the dynamics of NF- $\mathrm{B}$ signaling observed in LPS-exposed J774. 
A1 M $\varphi$ s. The protective effect of BAT against LPS-induced inflammation in vivo should be investigated in the future on other animal models of acute and chronic inflammation. The data presented herein propose the protective effect of BAT and its potential underlying molecular mechanism, suggesting that BAT could be used as a lead compound for the prevention of expanded acute inflammation. Undoubtedly, further experiments are required to address the potential anti-inflammatory effect of BAT and taurine in clinical setting, since the majority of anti-inflammatory drugs are examined after inflammation. Following LPS-mediated inflammation, further experiments will shed light on the potential anti-inflammatory effect of BAT and taurine in vitro and in vivo.

In conclusion, the present study demonstrates that BAT and taurine inhibit the nuclear translocation of the phosphorylated $\mathrm{NF}-\kappa \mathrm{B}$ p65 subunit (Ser536) in J774.A1 M $\varphi s$. To the best of our knowledge, this is the first study to demonstrate the protective properties of BAT and taurine against LPS-mediated inflammation in vivo, using a murine LPS-mediated air pouch model.

\section{Acknowledgements}

The authors would like to thank Professor Dr Waldemar Gottardi and Professor Dr Markus Nagl at the Department of Hygiene, Microbiology and Public Health, Institute of Hygiene and Medical Microbiology, Medical University of Innsbruck, Austria (m.nagl@i-med.ac.at; waldemar.gottardi@i-med.ac.at) for the provision of bromamine T (BAT).

\section{Funding}

This study was supported by the I.K.Y. State Scholarship Foundation for S. Baliou's Ph.D. studies. The IKY code is 2018-050-0502-13155.

\section{Availability of data and materials}

All data generated or analyzed during this study are included in this published article or are available from the corresponding author on reasonable request.

\section{Authors' contributions}

SB performed the in vitro and in vivo experiments, analyzed the data, performed the statistical analysis and prepared the manuscript. MS contributed to the H\&E staining and the counting of cell distribution/membrane thickness in the samples in the in vivo experiments. SB, MG, DAS, PI and AMK contributed to the editing of the manuscript. SB, MG, PI and VZ contributed to the interpretation of the data. SB and PI performed the statistical analysis of data. DAS and AMK were involved in the conception and design of the study. VZ conceived the study, and also contributed to the interpretation and the editing of the manuscript. All authors have read and approved the final manuscript.

\section{Ethics approval and consent to participate}

The present study was conducted according to the guidelines of the Declaration of Helsinki and was approved by the Bioethics Committee of the National Hellenic Research Foundation (date of approval: 29/3/2020). The ethic code is PN 2-3/29-3-2020.

\section{Patient consent for publication}

Not applicable.

\section{Competing interests}

DAS is the Editor-in-Chief for the journal, but had no personal involvement in the reviewing process, or any influence in terms of adjudicating on the final decision, for this article. The other authors declare that they have no competing interests.

\section{References}

1. Lawrence T, Willoughby DA and Gilroy DW: Anti-inflammatory lipid mediators and insights into the resolution of inflammation. Nat Rev Immunol 2: 787-795, 2002.

2. Davies NM, Reynolds JK, Undeberg MR, Gates BJ, Ohgami Y and Vega-Villa KR: Minimizing risks of NSAIDs: Cardiovascular, gastrointestinal and renal. Expert Rev Neurother 6: 1643-1655, 2006.

3. Kyriakopoulos AM, Nagl M, Baliou S and Zoumpourlis V: Alleviating promotion of inflammation and cancer induced by nonsteroidal anti-inflammatory drugs. Int J Inflam 2017: $9632018,2017$.

4. Hardy RS, Raza K and Cooper MS: Therapeutic glucocorticoids: Mechanisms of actions in rheumatic diseases. Nat Rev Rheumatol 16: 133-144, 2020.

5. Crane E and List A: Immunomodulatory drugs. Cancer Invest 23: 625-634, 2005.

6. Qandil AM: Prodrugs of nonsteroidal anti-inflammatory drugs (NSAIDs), more than meets the eye: A critical review. Int J Mol Sci 13: 17244-17274, 2012.

7. Vane JR and Botting RM: Mechanism of action of nonsteroidal anti-inflammatory drugs. Am J Med 104 2S-8S; discussion 21S-22S, 1998.

8. Ericson-Neilsen W and Kaye AD: Steroids: Pharmacology, complications, and practice delivery issues. Ochsner J 14: 203-207, 2014.

9. Bascones-Martinez A, Mattila R, Gomez-Font R and Meurman JH: Immunomodulatory drugs: Oral and systemic adverse effects. Med Oral Patol Oral Cir Bucal 19: e24-e31, 2014.

10. Leon R, Wu H, Jin Y, Wei J, Buddhala C, Prentice H and Wu JY: Protective function of taurine in glutamate-induced apoptosis in cultured neurons. J Neurosci Res 87: 1185-1194, 2009.

11. Chang CY, Shen CY, Kang CK, Sher YP, Sheu WH, Chang CC and Lee TH: Taurine protects HK-2 cells from oxidized LDL-induced cytotoxicity via the ROS-mediated mitochondrial and p53-related apoptotic pathways. Toxicol Appl Pharmacol 279: 351-363, 2014.

12. Schaffer S, Azuma J, Takahashi K and Mozaffari M: Why is taurine cytoprotective? Adv Exp Med Biol 526: 307-321, 2003.

13. Baliou S, Kyriakopoulos AM, Spandidos DA and Zoumpourlis V: Role of taurine, its haloamines and its lncRNA TUG1 in both inflammation and cancer progression. On the road to therapeutics? (Review). Int J Oncol 57: 631-664, 2020.

14. Nakajima Y, Osuka K, Seki Y, Gupta RC, Hara M, Takayasu M and Wakabayashi T: Taurine reduces inflammatory responses after spinal cord injury. J Neurotrauma 27: 403-410, 2010.

15. Zhang F, Mao Y, Qiao H, Jiang H, Zhao H, Chen X, Tong L and Sun X: Protective effects of taurine against endotoxin-induced acute liver injury after hepatic ischemia reperfusion. Amino Acids 38: 237-245, 2010.

16. Bhavsar TM, Cantor JO, Patel SN and Lau-Cam CA: Attenuating effect of taurine on lipopolysaccharide-induced acute lung injury in hamsters. Pharmacol Res 60: 418-428, 2009.

17. Abdih H, Kelly CJ, Bouchier-Hayes D, Barry M and Kearns S: Taurine prevents interleukin-2-induced acute lung injury in rats. Eur Surg Res 32: 347-352, 2000.

18. Sun M, Zhao Y, Gu Y and Xu C: Anti-inflammatory mechanism of taurine against ischemic stroke is related to down-regulation of PARP and NF- $\kappa$ B. Amino Acids 42: 1735-1747, 2012. 
19. Son MW, Ko JI, Doh HM, Kim WB, Park TS, Shim MJ and Kim BK: Protective effect of taurine on TNBS-induced inflammatory bowel disease in rats. Arch Pharm Res 21: 531-536, 1998

20. Shimizu M, Zhao Z, Ishimoto Y and Satsu H: Dietary taurine attenuates dextran sulfate sodium (DSS)-induced experimental colitis in mice. Adv Exp Med Biol 643: 265-271, 2009.

21. Zhao Z, Satsu H, Fujisawa M, Hori M, Ishimoto Y, Totsuka M, Nambu A, Kakuta S, Ozaki H and Shimizu M: Attenuation by dietary taurine of dextran sulfate sodium-induced colitis in mice and of THP-1-induced damage to intestinal Caco-2 cell monolayers. Amino Acids 35: 217-224, 2008.

22. Son M, Kim HK, Kim WB, Yang J and Kim BK: Protective effect of taurine on indomethacin-induced gastric mucosal injury. Adv Exp Med Biol 403: 147-155, 1996.

23. Redmond HP, Stapleton PP, Neary P and Bouchier-Hayes D Immunonutrition: The role of taurine. Nutrition 14: 599-604, 1998.

24. Klebanoff SJ: Myeloperoxidase: Friend and foe. J Leukoc Biol 77: 598-625, 2005.

25. Weiss SJ, Klein R, Slivka A and Wei M: Chlorination of taurine by human neutrophils. Evidence for hypochlorous acid generation. J Clin Invest 70: 598-607, 1982.

26. Marcinkiewicz $\mathrm{J}$ and Kontny E: Taurine and inflammatory diseases. Amino Acids 46: 7-20, 2014

27. Marcinkiewicz J, Grabowska A, Bereta J and Stelmaszynska T: Taurine chloramine, a product of activated neutrophils, inhibits in vitro the generation of nitric oxide and other macrophage inflammatory mediators. J Leukoc Biol 58: 667-674, 1995.

28. Marcinkiewicz J, Mak M, Bobek M, Biedroń R, Białecka A, Koprowski M, Kontny E and Maśliński W: Is there a role of taurine bromamine in inflammation? Interactive effects with nitrite and hydrogen peroxide. Inflamm Res 54: 42-49, 2005.

29. Kim C, Park E, Quinn MR and Schuller-Levis G: The production of superoxide anion and nitric oxide by cultured murine leukocytes and the accumulation of TNF-alpha in the conditioned media is inhibited by taurine chloramine. Immunopharmacology 34 89-95, 1996

30. Kim C and Cha YN: Production of reactive oxygen and nitrogen species in phagocytes is regulated by taurine chloramine. Adv Exp Med Biol 643: 463-472, 2009.

31. Park E, Quinn MR, Wright CE and Schuller-Levis G: Taurine chloramine inhibits the synthesis of nitric oxide and the release of tumor necrosis factor in activated RAW 264.7 cells. J Leukoc Biol 54: 119-124, 1993.

32. Olszanecki R, Kurnyta M, Biedroń R, Chorobik P, Bereta M and Marcinkiewicz J: The role of heme oxygenase-1 in down regulation of PGE2 production by taurine chloramine and taurine bromamine in J774.2 macrophages. Amino Acids 35: 359-364, 2008.

33. Kontny E, Chorąży-Massalska M, Rudnicka W, Marcinkiewicz J and Maśliński W: Comparison of taurine chloramine and taurine bromamine effects on rheumatoid arthritis synoviocytes. Amino Acids 32: 447-452, 2007.

34. Marcinkiewicz J, Wojas-Pelc A, Walczewska M, LipkoGodlewska S, Jachowicz R, Maciejewska A, Białecka A and Kasprowicz A: Topical taurine bromamine, a new candidate in the treatment of moderate inflammatory acne vulgaris: A pilot study. Eur J Dermatol 18: 433-439, 2008.

35. Kyriakopoulos A, Logotheti S, Marcinkiewicz J and Nagl M: $\mathrm{N}$-chlorotaurine and $\mathrm{N}$-bromotaurine combination regimen for the cure of Valacyclovir-unresponsive Herpes Zoster Comorbidity in a multiple Sclerosis patient. Int J Med Pharm Case Rep 7: 1-6, 2016.

36. Pasich E, Walczewska M, Białecka A, Peruń A, Kasprowicz A and Marcinkiewicz J: Taurine haloamines and biofilm: II. Efficacy of taurine bromamine and chlorhexidine against selected microorganisms of oral biofilm. Adv Exp Med Biol 803: 133-143, 2015.

37. Martini C, Hammerer-Lercher A, Zuck M, Jekle A, Debabov D, Anderson $\mathrm{M}$ and $\mathrm{Nagl} \mathrm{M}$ : Antimicrobial and anticoagulant activities of N-Chlorotaurine, N, N-Dichloro-2,2-dimethyltaurine, and $\mathrm{N}$-monochloro-2,2-Dimethyltaurine in human blood. Antimicrob Agents Chemother 56: 1979-1984, 2012.

38. Walczewska M, Peruń A, Białecka A, Śróttek M, Jamróz W, Dorożyński P, Jachowicz R, Kulinowski P, Nagl M, Gottardi W and Marcinkiewicz J: Comparative analysis of microbicidal and anti-inflammatory properties of novel taurine bromamine derivatives and bromamine T. Adv Exp Med Biol 975 Pt 1: 515-534, 2017.
39. Nair CG, Lalithakumari R and Senan PI: Bromamine-T as a new oxidimetric titrant. Talanta 25: 525-527, 1978 .

40. Baliou S, Goulielmaki M, Ioannou P, Cheimonidi C, Trougakos IP, Nagl M, Kyriakopoulos AM and Zoumpourlis V: Bromamine T (BAT) exerts stronger anti-cancer properties than taurine (Tau) Cancers (Basel) 13: 182, 2021.

41. Kyriakopoulos AM, Nagl M, Orth-Höller D, Marcinkiewicz J, Baliou S and Zoumbourlis V: Successful treatment of a unique chronic multi-bacterial scalp infection with N-chlorotaurine, $\mathrm{N}$-bromotaurine and bromamine T. Access Microbiol 2: acmi000126, 2020

42. Livak KJ and Schmittgen TD: Analysis of relative gene expression data using real-time quantitative PCR and the 2(-Delta Delta C(T)) method. Methods 25: 402-408. 2001

43. Sedgwick AD, Sin YM, Edwards JC and Willoughby DA: Increased inflammatory reactivity in newly formed lining tissue. J Pathol 141: 483-495, 1983

44. Huang Z, Zhao C, Chen Y, Cowell JA, Wei G, Kultti A, Huang L, Thompson CB, Rosengren S, Frost GI and Shepard HM: Recombinant human hyaluronidase $\mathrm{PH} 20$ does not stimulate an acute inflammatory response and inhibits lipopolysaccharide-induced neutrophil recruitment in the air pouch model of inflammation. J Immunol 192: 5285-5295, 2014.

45. Akbar M, Fraser AR, Graham GJ, Brewer JM and Grant MH: Acute inflammatory response to cobalt chromium orthopaedic wear debris in a rodent air-pouch model. J R Soc Interface 9: 2109-2119, 2012

46. Eteraf-Oskouei T,Mikaily Mirak Sand Najafi M: Anti-inflammatory and anti-angiogenesis effects of verapamil on rat air pouch inflammation model. Adv Pharm Bull 7: 585-591, 2017.

47. Li B, Hu Y, Zhao Y, Cheng M, Qin H, Cheng T, Wang Q, Peng X and Zhang $X$ : Curcumin attenuates titanium particle-induced inflammation by regulating macrophage polarization in vitro and in vivo. Front Immunol 8: 55, 2017.

48. Calil IL, Zarpelon AC, Guerrero AT, Alves-Filho JC, Ferreira SH, Cunha FQ, Cunha TM and Verri WA Jr: Lipopolysaccharide induces inflammatory hyperalgesia triggering a TLR4/MyD88-dependent cytokine cascade in the mice paw. PLoS One 9: e90013, 2014.

49. Sartori T, Galvão dos Santos G, Nogueira-Pedro A, Makiyama E, Rogero MM, Borelli P and Fock RA: Effects of glutamine, taurine and their association on inflammatory pathway markers in macrophages. Inflammopharmacology 26: 829-838, 2018.

50. Chesney RW: Taurine: Its biological role and clinical implications. Adv Pediatr 32: 1-42, 1985.

51. Duarte DB, Vasko MR and Fehrenbacher JC: Models of inflammation: Carrageenan air pouch. Curr Protoc Pharmacol 72: 5.6.1-5.6.9, 2016

52. Zhang Y, Zhou X and Zhou B: DC-derived TSLP promotes Th2 polarization in LPS-primed allergic airway inflammation. Eur J Immunol 42: 1735-1743, 2012.

53. Segawa R, Mizuno N, Hatayama T, Jiangxu D, Hiratsuka M, Endo Y and Hirasawa N: Lipopolysaccharide-activated leukocytes enhance thymic stromal lymphopoietin production in a mouse air-pouch-type inflammation model. Inflammation 39: 1527-1537, 2016

54. Chen YS, Lin HH, Liu PJ, Tsai HY, Hsueh PT, Liu HY and Chen YL: Use of 3-hydroxy fatty acid concentrations in a murine air pouch infection model as a surrogate marker for LPS activity: A feasibility study using environmental Burkholderia cenocepacia isolates. J Microbiol Methods 87: 368-374, 2011.

55. Vassalli P: The pathophysiology of tumor necrosis factors. Annu Rev Immunol 10: 411-452, 1992

56. Germano G, Allavena P and Mantovani A: Cytokines as a key component of cancer-related inflammation. Cytokine 43: 374-379, 2008.

57. Apostolaki M, Armaka M, Victoratos P and Kollias G: Cellular mechanisms of TNF function in models of inflammation and autoimmunity. Curr Dir Autoimmun 11: 1-26, 2010.

58. Vasigar P and Batmanabane M: Anti-inflammatoryactivity of calciumchannel blocker lercanidipine hydrochloride. J Pharmacol Pharmacother 4: 238-242, 2013.

59. Zhang XD, Zhao SY, Li YL, Zhu DL, Zhang R, Sheng JJ and Wang SJ: Taurine affects expression of ICAM-1, VCAM-1 by p38 pathway in hypoxic endothelial cells. Zhongguo Zhong Yao Za Zhi 42: 2350-2354, 2017.

60. Ulrich-Merzenich G, Zeitler H, Vetter H and Bhonde RR: Protective effects of taurine on endothelial cells impaired by high glucose and oxidized low density lipoproteins. Eur J Nutr 46: 431-438, 2007. 
61. Ozawa T, Koyama K, Ando T, Ohnuma Y, Hatsushika K, Ohba T, Sugiyama H, Hamada Y, Ogawa H, Okumura K and Nakao A: Thymic stromal lymphopoietin secretion of synovial fibroblasts is positively and negatively regulated by Toll-like receptors/nuclear factor-kappaB pathway and interferon-gamma/dexamethasone. Mod Rheumatol 17: 459-463, 2007.

62. Zenobia C and Hajishengallis G: Basic biology and role of interleukin-17 in immunity and inflammation. Periodontol 200069 142-159, 2015.

63. Eskan MA, Jotwani R, Abe T, Chmelar J, Lim JH, Liang S, Ciero PA, Krauss JL, Li F, Rauner M, et al: The leukocyte integrin antagonist Del-1 inhibits IL-17-mediated inflammatory bone loss. Nat Immunol 13: 465-473, 2012.
64. Li L, Huang L, Vergis AL, Ye H, Bajwa A, Narayan V, Strieter RM, Rosin DL and Okusa MD: IL-17 produced by neutrophils regulates IFN-gamma-mediated neutrophil migration in mouse kidney ischemia-reperfusion injury. J Clin Invest 120: 331-342, 2010.

(c) (3) This work is licensed under a Creative Commons Attribution-NonCommercial-NoDerivatives 4.0 International (CC BY-NC-ND 4.0) License. 